\title{
Medical Toxicology Education and Global Health: It is Still a World of Limited Resources in Low- and Middle-Income Countries
}

\author{
Natalie R. Neumann ${ }^{1}$ (D) Trevonne M. Thompson ${ }^{2}$ \\ Received: 21 February 2020 / Revised: 19 May 2020 / Accepted: 20 May 2020 / Published online: 3 June 2020 \\ (C) American College of Medical Toxicology 2020
}

Keywords Toxicology $\cdot$ Global health $\cdot$ Poisoning $\cdot$ Developing countries $\cdot$ Medical Education

Poisoning is a worldwide problem. In 2015, a previous editorial in this journal highlighted the importance of medical toxicology education globally [1]. The data on global poisonings are no better now than they were then. While statistics are difficult to compile, the estimates are noteworthy: intentional pesticide ingestion alone causes roughly 370,000 deaths per year worldwide [2]. Approximately 100,000 fatalities and considerable morbidity result from an estimated 5 million annual snakebites, which occur predominately in low- and middle-income nations [2-5]. In 2012, an additional 193,000 individuals are thought to have died of unintentional poisoning in developing countries [2]. To treat these exposures, there are a total of 312 poison centers worldwide, but nearly half of them (44\%) are in North America and in Europe [6]. Furthermore, as of 2011, only 21 of the world's 193 countries reported having medical toxicologists [7]. Keeping in mind that many low- and middle-income countries have fewer workplace and environmental regulations, less access to modern medical resources, and increasing prevalence of drugs of abuse, these figures create a stark picture: one in which many poisonings occur in places with few resources to care for the poisoned patient [8].

The contrast with North America is profound. Medical toxicology is admittedly a small specialty - there being only several hundred board certified medical toxicologists

Supervising Editor: Mark B. Mycyk, MD

Natalie R. Neumann

natalie.neumann@cuanschutz.edu

1 Rocky Mountain Poison and Drug Center, Denver Health and Hospital Authority, Suite 600, 1391 Speer Boulevard, Denver, CO 80204, USA

2 University of Illinois College of Medicine at University of Illinois at Chicago, Chicago, IL, USA in the USA. Still, its practitioners are highly trained and readily accessible. Medical toxicologists must complete two years of dedicated training after finishing training in a primary specialty, pass a certifying examination, and maintain accreditation through a program of continuing education. They frequently operate in concert with the US poison center network-organized by the American Association of Poison Control Centers-which allows laypeople, healthcare facilities, and individual physicians easy access to poisoning information and medical toxicology consultations. This model enables a small number of highly trained medical toxicologists to participate in the care of the estimated 3.5 million yearly toxicologic exposures in the USA, only 1500 of which result in death [9].

Given the obvious disparity in care between North America and developing nations, one might wonder why poisonings in resource-limited settings do not garner more attention. Put simply, global health groups must triage their efforts. Historically, the top priorities in low- and middle-income countries have been to prevent and treat communicable diseases, coordinate disaster responses, and improve access to healthcare $[10,11]$. Attention has recently started to shift toward non-communicable diseases and injuries (including poisonings) as these illnesses are estimated to cause over $81 \%$ of all deaths globally (55.98\% in low-income, $68.95 \%$ in low-middle-income, and $88.37 \%$ in middle-income countries) [12]. Still, compared with cardiovascular disease, which accounts for $32 \%$ of deaths worldwide, and malignancy, which accounts for $17 \%$, poisonings may seem inconsequential [12].

These numbers, however, must be kept in context; poisonings may account for fewer fatalities, but many of these deaths are preventable. Many poisonings are treatable. Many poisonings occur in otherwise healthy individuals who may suffer profound morbidity as a result of the 
toxicologic exposure. Conversely, if treated promptly and properly, poisoned patients have the potential to return to baseline function without permanent disability [9]. Their recovery can have a disproportionate effect on disabilityadjusted life years, population health, and economic productivity compared with other non-communicable diseases [13].

Another important factor to take into consideration when appraising the global impact of poisoning is that a lack of trust in healthcare systems undermines global health efforts. According to the Lancet Global Health Commission on High Quality Health Systems, "poorquality care is now a bigger barrier to reducing mortality than insufficient access" [14]. The commission notes that poor quality of care threatens not only individual patient outcomes, but diminishes the greater population's trust in, and utilization of, healthcare systems. Conversely, improving outcomes may enhance confidence in medical services [14]. A logical progression of this concept is that advancing the treatment of poisoning may foster trust in healthcare systems. Imagine, for example, the successful treatment of a critically ill, poisoned patient with a reversible condition. With prompt and appropriate management, that patient may return to baseline function. Cases like this one suggest that medical toxicology may be well suited to cultivate faith in healthcare systems.

How can the care of the poisoned patient be improved globally? An obvious step would involve increasing physicians' knowledge of medical toxicology. The creation of medical toxicology training programs that allow physicians to specialize in the field is an ideal solution. This approach, however, is impractical. It is too resourceintensive and requires long-term, deliberate strategic planning which could compete with contemporary medical resource needs. A more practical and immediate solution could involve delivering educational modules to physicians in locations with limited access to medical toxicology resources. Flexible and low-cost training modules could be delivered on-site and tailored to the needs of a specific geographic region. When developing such approaches, content experts (i.e., medical toxicologists) and medical educators can collaborate to define clear outcome measures. Learner assessment and program evaluation can be used to measure the impact of the teaching and modify teaching strategies as needed. While this approach does not rise to the level of subspecialty training, it would nevertheless enhance local physicians' knowledge of medical toxicology and potentially improve care.

To this end, Kopek and colleagues describe a program called The Global Educational Toxicology ToolKIT (GETKIT) in the current issue of JMT [15]. GETKIT is a one-day course for teaching poisoning essentials in low- and middle-income countries. A pilot study funded by the Medical
Toxicology Foundation (MTF), GETKIT is portable and flexible: the program can be delivered with relatively few resources and can be adjusted to suit a location's particular needs and resource constraints. For these reasons, it is a program which takes an important initial step in addressing medical toxicology educational needs in low-resource areas.

Poisoning is a worldwide problem. A multifaceted approach is required for the prevention and management of poisoning, particularly in low- and middle-income countries. Until medical toxicology resources and trained subspecialty physicians are more available globally, low-cost, portable, and flexible educational resources are part of the solution to the management of poisoned patients.

\section{References}

1. Thompson TM. Medical toxicology education in a world of limited resources. J Med Toxicol. 2015;11(3):281-2. https://doi.org/10. 1007/s13181-015-0487-7.

2. World Health Organization (2020) International programme on chemical safety: poisoning prevention and management. https:// www.who.int/ipcs/poisons/en. Accessed 30 Apr 2020.

3. Longbottom J, Shearer FM, Devine M, Alcoba G, Chappuis F, Weiss DJ, et al. Vulnerability to snakebite envenoming: a global mapping of hotspots. Lancet. 2018;392(10148):673-84. https://doi. org/10.1016/s0140-6736(18)31224-8.

4. Chippaux JP. Estimating the global burden of snakebite can help to improve management. PLoS Med. 2008;5(11):e221. https://doi. org/10.1371/journal.pmed.0050221.

5. World Health Organization (2019, May) Snakebite envenoming a strategy for prevention and control. https://www.who.int/ snakebites/resources/9789241515641/en. Accessed 30 Apr 2020.

6. World Health Organization (2019, February 28) Poison centres: world directory of poison centers. https://www.who.int/gho/phe/ chemical_safety/poisons_centres/en. Accessed 30 Apr 2020.

7. Abstracts (2011). Clinical Toxicology 49 (6):515-627. https://doi. org/10.3109/15563650.2011.598695.

8. Degenhardt L, Charlson F, Ferrari A, Santomauro D, Erskine H, Mantilla-Herrara A, et al. The global burden of disease attributable to alcohol and drug use in 195 countries and territories, 1990-2016: a systematic analysis for the Global Burden of Disease Study 2016. Lancet Psychiatry. 2018;5(12):987-1012. https://doi.org/10.1016/ s2215-0366(18)30337-7.

9. Gummin DD, Mowry JB, Spyker DA, Brooks DE, Osterthaler KM, Banner W. 2017 annual report of the American Association of Poison Control Centers' National Poison Data System (NPDS): 35th annual report. Clin Toxicol (Phila). 2018;56(12):1213-415. https://doi.org/10.1080/15563650.2018.1533727.

10. Center for Global Health USCfDCaP (2017) Top 10 global health priorities. https://www.cdc.gov/globalhealth/resources/photobook/ pdf/CDC_Global_Health_Photo_Book-web.pdf. Accessed 30 Apr 2020.

11. World Health Organization (2020) WHO Priorities. https://www. who.int/dg/priorities/en. Accessed 30 Apr 2020.

12. Institute for Health Metrics and Evaluation (2020) Global health data exchange: GBD results tool. http://ghdx.healthdata.org/gbdresults-tool. Accessed 30 Apr 2020.

13. World Health Organization (2020) Metrics: disability-adjusted life year (DALY). https://www.who.int/healthinfo/global_burden disease/metrics_daly/en. Accessed 30 Apr 2020. 
14. Kruk ME, Gage AD, Arsenault C, Jordan K, Leslie HH, RoderDeWan S, et al. High-quality health systems in the Sustainable Development Goals era: time for a revolution. Lancet Glob Health. 2018;6(11):e1196-252. https://doi.org/10.1016/s2214$109 x(18) 30386-3$.

15. Kopec KT, Vohra R, Santos C, Kazzi Z, Wong A. The Global Educational Toxicology Toolkit (GETKIT): a 1-day course for teaching poisoning essentials in low- and middle-income countries (LMIC): course development and pilot data analysis. J Med Toxicol 2020;16(3). https://doi.org/10.1007/s13181-019-00745-8.

Publisher's Note Springer Nature remains neutral with regard to jurisdictional claims in published maps and institutional affiliations. 